the variables showing a $\mathrm{p}$ value $<0.100$ at univariate analysis, i.e. pre-procedural cardiogenic shock [OR 9.00, C.I. (2.137.6), $\mathrm{p}=0.003$ ] and CK peak [OR 1.00, C.I. (1.0-1.0), $\mathrm{p}=0.051]$. Pre-procedural cardiogenic shock was the only predictor [OR 7.058, C.I. (1.2-40.6), $\mathrm{p}=0.029$ ] of in-hospital MACCE. No significant predictors of MACCE at follow-up were found at logistic regression analysis.

Conclusion In our 10 year experience of Impella-assisted highrisk PCI, 20\% patients had in-hospital MACCE and mean survival was 21 months. At follow up, MACCE rate was less than $4 \%$ and both angina and heart failure symptoms were well controlled. Pre-procedural cardiogenic shock was the only predictor of in-hospital MACCE.

Conflict of Interest No conflict of interest

\section{OUT-OF-HOSPITAL CARDIAC ARREST SURVIVORS UNDERGOING EMERGENCY PCI HAVE AN EXCELLENT NEUROLOGICAL RECOVERY}

${ }^{1}$ liandra rams ramachenderam*, ${ }^{2}$ Anthony Mechery, ${ }^{3}$ Peter Isherwood, ${ }^{3}$ Neil Abeysinghe, ${ }^{3}$ Alexander Zaphiriou, ${ }^{3}$ Sudhakar George, ${ }^{2} \mathrm{M}$. Adnan Nadir, ${ }^{2}$ Peter Ludman, ${ }^{2}$ Sagar Doshi, ${ }^{2}$ Jonathan Townend, ${ }^{2}$ sohail khan. ${ }^{1}$ University of Birmingham; ${ }^{2}$ Queen Elizabeth Hospital Birmingham; ${ }^{3}$ University Hospital Birmingham

10.1136/heartinl-2019-BCS.70

Introduction Out-of-hospital cardiac arrest (OHCA) is associated with a low survival to discharge rate. We aimed to evaluate the outcome of early Percutaneous Coronary Intervention (PCI) on the mortality rates of patients with OHCA and their neurological recovery post-intervention.

Methods Outcomes of all patients presenting to our centre with OHCA who received PCI over a 3-year period were analysed (January 2015 - December 2017). Univariate analysis was performed.

Results 65 patients were identified $(80 \%$ Males, Mean age $59.9 \pm 14.2$ years). Chest compressions were undertaken in $60.0 \%$ of patients. The most common rhythm identified was Ventricular Fibrillation (86.2\%), followed by PEA (9.2\%), Ventricular Tachycardia (4.6\%) and Asystole (4.6\%). The mean time for patients to arrive at the cardiac centre was $51.4 \pm$ 20.7 minutes. Post-arrest ECG revealed ST-elevation (STEMI) in $53(81.5 \%)$ patients. $42(64.4 \%)$ received ventilation preangiography and $45(69.2 \%)$ were transferred to Intensive Care Unit (ITU) post-angiography. 18 (27.7\%) were in cardiogenic shock. There was no statistical significance in the mortality rates between patients with STEMI and non-STEMI (53 vs $12 ; \mathrm{p}=0.43)$, see Table 1.54 patients $(83.1 \%)$ survived to discharge, 30-day survival 53(81.6\%), 6-month survival 53 $(81.6 \%) .31$ ventilated patients $(73.8 \%)$ survived to discharge, 30-days and 6-months whereas all (100\%) non-ventilated patients $(n=23)$ survived to discharge and 30-days and 22 survived $(95.7 \%)$ at 6 -months $(73.8$ vs $100 \% ; p=0.04) .12$ patients in shock (66.7\%) survived to discharge, 30-days and 6-months whereas 42 non-shocked patients (89.4\%) survived to discharge, 30-days and 6-months (66.7 vs $89.4 \%, \mathrm{p}=0.06)$.

\begin{tabular}{|c|c|c|}
\hline & \multicolumn{2}{|c|}{$\begin{array}{l}\text { Baseline Characteristics of Out-of-Hospital Cardiac Arrests (OHCA) patients } \\
\text { undergoing Percutaneous Coronary Intervention at Queen Elizabeth Hospital, } \\
\text { Birmingham. n=number of patients. }\end{array}$} \\
\hline & Characteristics & OHCA undergoing $\mathrm{PCl}$ \\
\hline & Average age (years) & $59.9 \pm 14.2$ \\
\hline & Male, $n(\%)$ & $52(80 \%)$ \\
\hline & Initial rhythm, n (\%) & $\begin{array}{l}\mathrm{VF}=53(81.6) \\
\mathrm{PEA}=6(9.2) \\
\mathrm{VT}=3(4.6) \\
\text { Asystole }=3(4.6)\end{array}$ \\
\hline & Bystander chest compression, $\mathrm{n}(\%)$ & $39(60)$ \\
\hline & Post-arrest ECG & $\begin{array}{l}\text { STEMI }=53(81.5) \\
\text { NSTEMI }=12(18.5)\end{array}$ \\
\hline & Ventilation, $\mathrm{n}(\%)$ & $42(64.4)$ \\
\hline & Cardiogenic shock (\%) & $18(27.7)$ \\
\hline & $\mathrm{pH}$ & $7.21 \pm 0.18$ \\
\hline & Lactate & $6.29 \pm 5.26$ \\
\hline & \multicolumn{2}{|c|}{$\begin{array}{l}\text { Outcome of OHCA patient's post-emergency PCl at Queen Elizabeth Hospital, Birmingham } \\
\mathrm{n}=\text { number of patients }\end{array}$} \\
\hline & Characteristics & Outcome post-emergency $\mathrm{PCl}$ \\
\hline & ITU, $\mathrm{n}(\%)$ & $45(69.2)$ \\
\hline & Cooling catheter, $\mathrm{n}(\%)$ & $33(73.3)$ \\
\hline & Average hospital stay (days) & $\begin{array}{l}\text { ITU }=21 \\
\text { Non-ITU }=8\end{array}$ \\
\hline & $\begin{array}{l}\text { Withdrawal of life sustaining } \\
\text { treatment }<72 \text { hours, } n(\%)\end{array}$ & $4(36.0)$ \\
\hline & $\begin{array}{l}\text { Cerebral Performance Category (CPC) } \\
\text { score, } \mathrm{n}(\%)\end{array}$ & $\begin{array}{l}1=48(73.8) \\
2=3(4.6) \\
3=2(3.1) \\
4=1(1.5) \\
5=11(16.9)\end{array}$ \\
\hline
\end{tabular}


Abstract 73 Table 1 Outcomes at 6 months

\begin{tabular}{|l|l|l|l|}
\hline & Dialysis N=44 & Creatinine $>150 \mathrm{~N}=86$ & P Value \\
\hline Cardiovascular death & $6(13.6 \%)$ & $7(8.1 \%)$ & \\
\hline Cardiac arrest & $1(2.3 \%)$ & $1(1.2 \%)$ & \\
\hline Heart failure & $3(6.8 \%)$ & $5(5.8 \%)$ & \\
\hline MI & $4(9.1 \%)$ & $1(1.2 \%)$ & \\
\hline Angina & $6(13.6 \%)$ & $8(9.3 \%)$ & \\
\hline Bleeding complication & $4(9.1 \%)$ & $2(2.3 \%)$ & \\
\hline Arrhythmia & $2(2.3 \%)$ & $2(2.3 \%)$ & \\
\hline MACE & $15(34.1 \%)$ & $11(12.8 \%)$ & $<0.01$ \\
\hline All-cause death & $11(25 \%)$ & $11(12.8 \%)$ & $<0.05$ \\
\hline
\end{tabular}

Cerebral Performance Category (CPC) score at 30-days was as follows; 48 (73.8\%) scored 1, 3 (4.6\%) scored 2, 2 (3.1\%) scored 3, 1 (1.5\%) scored 4 and 11 (16.9\%) scored 5. Significantly more patients were in CPC 1 to 3 than $4-5$ (53 vs 12 ; $\mathrm{p}<0.001$ ), see Table 2 .

Conclusion In our cohort of patients presenting with OHCA who underwent PCI, we observed an excellent survival to discharge rate. Poor neurological recovery is seen in only a minority of patients who have received PCI after successful OHCA.

Conflict of Interest None

\section{\begin{tabular}{|l|l}
\hline 73 & OUTCOMES IN PATIENTS UNDERGOING PERCUTANEOUS
\end{tabular} CORONARY INTERVENTION WITH CHRONIC KIDNEY DISEASE}

${ }^{1}$ Thomas Kirwin*, ${ }^{2}$ Anthony Mechery, ${ }^{2}$ Vincenzo Ventrungo, ${ }^{2}$ Muhammad Waqas, ${ }^{2} J o n a t h a n$ Townend, ${ }^{2}$ sohail khan. 'Queen Elizabeth Hospital Birmingham, Birmingham, UK: ${ }^{2}$ Queen Elizabeth Hospital Birmingham

10.1136/heartjnl-2019-BCS.71

Introduction Patients with chronic kidney disease (CKD) have been excluded from clinical trials evaluating the outcomes of percutaneous coronary intervention (PCI). Although studies show that CKD increases complications in patients undergoing PCI, there is still uncertainty of the long term efficacy of PCI for patients with this common problem.

Purpose To describe and compare the outcomes of patients with varying degrees of CKD following PCI and to determine in what time period they are most at risk of complications.

Method 1862 patients received PCI in our centre from June 2016 to June 2018, 130 of which had renal failure. We retrospectively compared the complication rates between two groups of patients, those who were on dialysis (44) and those with CKD stage 3 and 4 and not on dialysis (86). Baseline characteristics of the patients were evaluated and patient records were reviewed to observe their outcome at 1 month and 6 months. We defined MACE as cardiovascular death, MI, stroke, major bleeding complication and cardiac arrest.

Results Comparing the baseline characteristics there was no significant difference in mean age between the dialysis group vs the CKD stage $3 / 4$ group (67 vs 70$)$. However, there was a higher proportion of men in the CKD stage $3 / 4$ group vs the dialysis cohort $(84 \%$ vs $59 \%, \quad \mathrm{p}<0.05)$. There was a significantly higher proportion of diabetics in the dialysis vs the CKD stage $3 / 4$ group $(70 \%$ vs $55 \%, \mathrm{P}<0.05)$. Comparing outcomes at 1 month between those on dialysis and those with CKD stage 3/4, dialysed patients had a numerically higher MACE $(15.9 \%$ vs $11.6 \%, \mathrm{p}>0.05)$ and all-cause mortality $(13.6 \%$ vs $9.3 \%, \mathrm{p}>0.05)$, however, neither were significantly different. At 6 months, the dialysis group had a significantly higher MACE than the CKD stage $3 / 4$ group $(34.1 \%$ vs $12.8 \%, \mathrm{P}<0.01)$. The dialysis group also had significantly higher all-cause mortality $(25 \%$ vs $12.6 \% \mathrm{p}<0.05)$.

Conclusion Patients with chronic kidney disease undergoing PCI have a high morbidity and mortality rate. When we split the groups, patients on dialysis have a worse outcome with higher morbidity and mortality at 6 months compared to those with CKD stage $3 / 4$ and not on dialysis. The period of highest risk for MACE extended throughout the 6 months in the dialysis cohort, whereas, those not on dialysis were at highest risk in the first month. The outcomes at 6 months can be seen in table 1 .

Conflict of Interest No conflict of interest for all authors

\section{DAY CASE DRUG COATED BALLOON ONLY ANGIOPLASTY FOR DE NOVO CORONARY ARTERY DISEASE}

${ }^{1}$ loannis Merinopoulos*, ${ }^{2}$ Upul Wickramarachchi, ${ }^{2}$ James Wardley, ${ }^{2}$ Vikram Khanna, ${ }^{1}$ Tharusha Guanawardena, ${ }^{2}$ Clint Maart, ${ }^{1}$ Vassilios Vassiliou, ${ }^{3}$ Simon Eccleshall. ${ }^{1}$ University of East Anglia, Norfolk \& Norwich University Hospital; ${ }^{2}$ Norfolk \& Norwich University Hospital; ${ }^{3}$ Norfolk @ Norwich University Hospital

\subsection{6/heartjnl-2019-BCS.72}

Introduction The high pressures on hospital beds necessitate fast and efficient, yet safe turn-around of all elective patients ideally as day cases. Although same day discharge in patients receiving a coronary stent is widely supported by evidence, no prior study has reported on this strategy in Drug Coated Balloon (DCB) only de novo angioplasty. An important safety consideration, particularly with DCB only angioplasty is acute vessel closure due to a higher risk of coronary dissection, which will usually be apparent peri-procedurally. In this abstract we report our experience with day case DCB only angioplasty from a single high-volume UK centre and propose criteria for safe discharge. 